\title{
MICROMORPHOLOGY AND MICROHARDNESS OF ENAMEL AFTER TREATMENT WITH HOME-USE BLEACHING AGENTS CONTAINING 10\% CARBAMIDE PEROXIDE AND 7.5\% HYDROGEN PEROXIDE
}

\author{
Robson Tetsuo SASAKI ${ }^{1}$, Alex José ARCANJOํㅜ, Flávia Martão FLÓRIO², Roberta Tarkany BASTING ${ }^{3}$
}

1- DDS, Undergraduate student, Department of Restorative Dentistry, School of Dentistry and Dental Research Center São Leopoldo Mandic, Campinas, SP, Brazil.

2- DDS, MS, ScD, Full Professor, Department of Preventive Dentistry, School of Dentistry and Dental Research Center São Leopoldo Mandic, Campinas, SP, Brazil.

3- DDS, MS, ScD, PhD, Full Professor, Department of Restorative Dentistry, School of Dentistry and Dental Research Center São Leopoldo Mandic, Campinas, SP, Brazil.

Corresponding address: Dra. Roberta Tarkany Basting - Faculdade de Odontologia e Centro de Pesquisas Odontológicas São Leopoldo Mandic - Rua José Rocha Junqueira, 13 - Bairro Ponte Preta - 13045-755 - Campinas, SP - Brasil - Phone/Fax:+55-19-3211-3600 - e-mail: rbasting@yahoo.com

Received: December 22, 2008 - Accepted: July 2, 2009

\begin{abstract}
O

bjective: The purpose of this study was to assess the effect of home-use bleaching agents containing $10 \%$ carbamide peroxide and $7.5 \%$ hydrogen peroxide on enamel microhardness and surface micromorphology. Material and Methods: Enamel slabs ( $\mathrm{n}=10)$ received the bleaching agents for $1 \mathrm{~h}$ /day and remained in artificial saliva solution for $23 \mathrm{~h} /$ day, during a total period of 21 days. Control group was composed of enamel slabs that were not subjected to treatment with the agents and were maintained in artificial saliva solution. Microhardness tests were performed before treatment application, 21 days of treatment and 14 days after the end of treatment. Scanning electron microscopy analyses were performed after 14 days after the end of bleaching treatment by 3 calibrated observers who attributed scores. Results: The Tukey's test $(\alpha=0.05)$ showed no significant differences in microhardness values among bleaching agents, at 21 days of treatment and a significant increase in microhardness for different agents after 14 days from the end of treatment. Fisher's exact test showed differences in micromorphology of enamel between control and experimental groups $(\mathrm{p}=0.0342)$. Conclusions: Bleaching agents containing $10 \%$ carbamide peroxide and $7.5 \%$ hydrogen peroxide may change surface micromorphology of enamel, although no changes in microhardness were observed.
\end{abstract}

Key words: Micromorphology. Microhardness. Enamel. Carbamide peroxide. Hydrogen peroxide.

\section{INTRODUCTION}

The search for a more esthetic smile has grown exponentially in the last few decades. In order to meet this demand, many studies have been developed about dental bleaching and its effects on dental structure. Nightguard vital bleaching introduced by Haywood and Heymann ${ }^{16}$ (1989) represents an efficient and safe method that has been the most commonly used bleaching treatment in the last decades. Modifications, improvements and variations of the technique, such as different concentrations of carbamide peroxide agents (10 to $22 \%$ ) with carbopol and hydrogen peroxide agents were developed.

Studies have evaluated the effect of carbamide peroxide used in the home bleaching technique (with trays) on the superficial micromorphology of dental structure in regimens lasting longer than an $1 \mathrm{~h}$. Scanning electronic microscopy
(SEM) analyses have shown changes in surface micromorphology of enamel ${ }^{7,12,19,20,27}$ such as the presence of erosions and porosity. However, no study has reported how enamel microhardness and micromorphology are presented at the end of a bleaching regimen of $1 \mathrm{~h} /$ day application during 21 days, as recommended by manufacturers of bleaching products with different compositions: carbamide or hydrogen peroxide agents.

Changes in organic and inorganic content after bleaching treatment may be evaluated by microhardness tests ${ }^{10}$. Some in vitro studies have shown significant differences in sound enamel and dentin microhardness values after bleaching treatment with $10 \%$ carbamide peroxide, ${ }^{2,3,25,27}$ in spite of the presence of saliva, fluorides or other remineralizing solutions being capable of maintaining the balance between the remineralization and demineralization processes ${ }^{8,24}$.

The purpose of this study was to evaluate microhardness 
and surface micromorphology of enamel subjected to a bleaching treatment with commercial brands of agents containing 10\% carbamide peroxide (Colgate Platinum) and $7.5 \%$ hydrogen peroxide (Day White $2 Z$ ).

\section{MATERIAL AND METHODS}

After approval by the local Research Ethics Committee, completely non-erupted human third molars, extracted for reasons not related to those of the research, and kept stored in thymol solution $(0.1 \% ; \mathrm{pH} 7.0)$ after extraction, were used in this experiment. The teeth were debrided with scalpel blades and periodontal curettes. A transversal section was made, dividing the root and coronal portions. Longitudinal sections were made using double-faced diamond disks to obtain enamel slabs measuring $3 \mathrm{~mm} \times 3 \mathrm{~mm}$.

Thirty dental enamel slabs were used, with a standardized area of $9 \mathrm{~mm}^{2}(3 \mathrm{~mm} \times 3 \mathrm{~mm})$. The slabs were examined with a stereomicroscope at $\times 10$ magnification in order to exclude those with cracks and stains. The slabs were embedded in polystyrene resin by using $2.0-\mathrm{cm}$-diameter PVC molds, leaving the external enamel surfaces uncovered by the resin. After $24 \mathrm{~h}$, the slabs were removed from the molds and flattened to obtain the smooth surfaces required for microhardness tests. The enamel slabs were ground wet in a mechanical grinding machine with aluminum oxide discs of sequentially decreasing granulation (400-, 600- and 1200grit) and polished with $6,3,1 / 2$ and $1 / 4 \mathrm{~mm}$ diamond pastes and felt discs under mineral oil cooling, in order to obtain flat, smooth surfaces. Between disc granulations and pastes, the specimens were ultrasonically cleaned by placing specimens in distilled deionized water for a 10-min period to eliminate debris. The 30 enamel slabs were randomly assigned to 3 bleaching agent groups $(n=10)$ and were kept in a humid environment for 1 day until the beginning of the bleaching regimens.

The bleaching agents are specified in Figure 1. The active principle in Colgate Platinum (Colgate-Palmolive Ind. e Com. Ltda., São Paulo, SP, Brazil) is $10 \%$ carbamide peroxide, and Day White 2Z (Discus Dental, Culver City, CA, USA) contains $7.5 \%$ hydrogen peroxide. The manufacturers recommend product application for $1 \mathrm{~h} /$ day.
Prior to the application of the bleaching agents, an individual mold was made for each specimen, using 0.4$\mathrm{mm}$-thick flexible polymer in a vacuum plasticizer, and the enamel and dentin slabs were subjected to microhardness tests to obtain baseline values. A calibrated syringe was used to place $0.02 \mathrm{~mL}$ of each bleaching agent on the enamel slabs. The individual mold was positioned onto each specimen, and all specimens were then immersed in 13.5 $\mathrm{mL}$ of artificial saliva solution $(\mathrm{pH}=7.0)$ in individual containers. These containers were closed and kept in a humid environment for 1-h/day. The individual molds were then removed and washed with distilled deionized water. The bleaching agents were removed from the dental slabs by washing with distilled deionized water, and using a soft toothbrush to gently make 5 back-and-forth movements over the specimens, without causing changes on the enamel surface.

During the remaining $23 \mathrm{~h}$ of the day, the slabs of the experimental groups were stored at $37^{\circ} \pm 1^{\circ} \mathrm{C}$ in individual closed receptacles containing $13.5 \mathrm{~mL}$ of artificial saliva, which was changed every 2 days. The artificial saliva used in this study was the remineralizing solution described by Featherstone, et al. ${ }^{9}$ and modified by Serra and Cury ${ }^{26}$. The slabs in the control group were also maintained under these conditions, during the whole experiment.

The bleaching treatment was carried out during 21 days, corresponding clinically to a dental bleaching period of 3 weeks. After the bleaching treatment, the slabs were kept in their individual containers immersed in $13.5 \mathrm{~mL}$ of artificial saliva at $37^{\circ} \pm 1^{\circ} \mathrm{C}$, which was again changed every 2 days, for a further period of 14 days to evaluate the posttreatment period and a possible remineralizing effect of this saliva solution on dental tissue microhardness.

Microhardness measurements were performed before the bleaching treatment (baseline), 21 days after the beginning of the treatment phase, and in the posttreatment phase (that is, 14 days after completion of the treatment and 35 days from the beginning of treatment).

Three microhardness indentations were performed in each slab for each time, and assessed quantitatively in Knoop Hardness Number (KHN) with a 25-g load applied during 5 $\mathrm{s}$ for each indentation.

For the SEM analysis, specimens were mounted on

\begin{tabular}{|c|c|c|}
\hline & Day White 2Z & Platinum Overnight \\
\hline Composition & $\begin{array}{c}\text { Deionized water, poloxamer, 7.5\% } \\
\text { hydrogen peroxide, propilenoglycol, } \\
\text { glycerin, potassium nitrate, xylitol, mint oil, } \\
\text { hydroxypropyl cellulose, eugenol, aloe } \\
\text { vera gel, potassium hydroxide, colorant, } \\
\text { silicon emulsion, anise flavor }\end{array}$ & $\begin{array}{c}\text { 10\% carbamide peroxide, calcium } \\
\text { pyrophosphate, poloxamer 407, PEG-12, } \\
\text { PEG 2M, glycerin, calcium phosphate } \\
\text { dihydrate, sodium acid pyrophosphate, } \\
\text { sodium laurel sulfate, sodium saccharine, } \\
\text { EDTA dihydrate disodium, aroma, water }\end{array}$ \\
\hline
\end{tabular}

The manufacturers do not provide all components of the formulations, making it impossible to present exact product data.

FIGURE 1- Basic composition and manufacturer of each bleaching agent 


\begin{tabular}{|c|c|}
\hline \multicolumn{2}{|c|}{ Scores } \\
Erosion & No erosion \\
\hline $\begin{array}{c}\text { Presence of surface with porosities and/or erosions, } \\
\text { varying from light to severe, suggesting alterations of } \\
\text { enamel surface, with non-uniform aspect }\end{array}$ & $\begin{array}{c}\text { Absence of porosities and/or superficial erosions, } \\
\text { suggesting absence of superficial alterations of enamel, } \\
\text { with uniform superficial aspect }\end{array}$ \\
\hline
\end{tabular}

FIGURE 2- Scores attributed by the examiners, according to the type of surface

TABLE 1- Mean microhardness values and standard deviations for each bleaching agent at the different time intervals

\begin{tabular}{llll}
\hline Bleaching agent & Baseline & $\begin{array}{l}\text { Time interval } \\
\text { 21 days }\end{array}$ & 14 days post-treatment \\
\hline Control & $334.7 \pm 51.7 \mathrm{Ba}$ & $322.6 \pm 75.9 \mathrm{ABa}$ & $339.5 \pm 44.3 \mathrm{Aa}$ \\
Day White & $2 Z 268.0 \pm 78.1 \mathrm{Bab}$ & $297.0 \pm 32.0 \mathrm{ABab}$ & $330.8 \pm 23.0 \mathrm{Aab}$ \\
Platinum & $258.7 \pm 111.5 \mathrm{Bb}$ & $274.4 \pm 39.3 \mathrm{ABb}$ & $308.4 \pm 55.1 \mathrm{Ab}$
\end{tabular}

Values followed by same capital letters horizontally and same small letters vertically are not significantly different by ANOVA and Tukey test $(p<0.05)$.

metallic stubs and sputter-coated with a 10-nm thick layer of gold. Observations were made under a high resolution field emission in-lens scanning electron microscope (DSM 940 A, Zeiss, Oberkochen, Germany) with a digital steadyscreen image with a resolution of $1,280 \times 1,024$ pixels and $\times 1,500$ magnification. The most central region or the region that was most representative of the entire surface after exploratory observation of the area was used. The SEM micrographs were examined by 3 calibrated examiners, who determined the type of surface presented by means of scores according to the presence of erosions on the enamel surface (Figure 2). The sequence of images was evaluated at two distinct periods to assess the intraexaminer agreement. ANOVA and Tukey's test were used to evaluate mean significance of microhardness for each bleaching agent at different time intervals. The statistical analysis was performed using the SAS statistical software (SAS Institute Inc., Cary, NC, USA).

In the analysis of surface micromorphology, Kappa statistics was applied to assess the intra and interexaminer agreement. For statistical analysis using Fisher's exact test, the mode of visual analysis by 3 examiners in two evaluations was used to establish whether or not there were changes in enamel surface micromorphology.

\section{RESULTS}

Table 1 shows the mean microhardness values and standard deviations for each bleaching agent at the different time intervals.

The microhardness of enamel subjected to the different bleaching treatments remained similar to measurements taken after 21 days ( $p>0.05)$ from the beginning of the experiment. However, after 14 days from the end of the treatment, a significant increase in microhardness was verified for different agents $(p<0.05)$. Mean microhardness values at 21 days and after 14 days from the end of treatment did not differ among them for any group. Statistically significant difference was observed between the bleaching agents and baseline ( $p>0.05)$, making it impossible to make comparisons among agents in the different timespan studies.

According to Landis and $\operatorname{Koch}^{18}$ (1977), the interexaminer agreement was considered from "moderate" to "substantial" and the intraexaminer agreement was considered from "substantial" to "nearly perfect".

SEM data of surface micromorphology classified by the examiners are presented in Table 2 . There were statistically significant differences among the analyses of surface micromorphology of enamel either subjected to treatment with bleaching agent $(\mathrm{p}=0.0342)$ or not, when comparing the parameters "Erosion" and "No erosion". The control group presented the lowest proportion of alterations in surface micromorphology $(20 \%)$, followed by the groups Day White 2Z (50\%) and Platinum (80\%). Figures 3-5 show SEM images representative of the alterations occurred on

TABLE 2- Number and percentage of SEM images with erosions on enamel surface, according to values of visual evaluation mode, with respect to different treatments

\begin{tabular}{lll}
\hline Treatment & Erosion & No erosion \\
\hline Control & $2(20.0)$ & $8(80.0)$ \\
Day White 2Z & $5(50.0)$ & $5(50.0)$ \\
Platinum & $8(80.0)$ & $2(20.0)$ \\
\hline
\end{tabular}

Values are expressed as $\mathrm{n}(\%)$. 


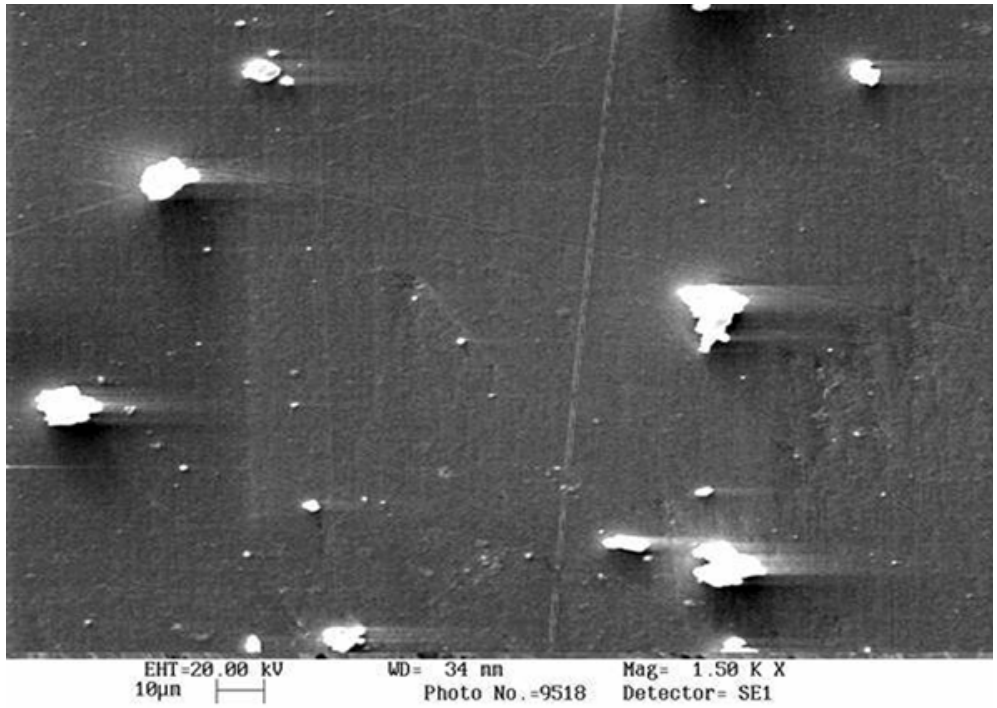

FIGURE 3- SEM micrograph of enamel surface subjected to immersion in artificial saliva (control group), presenting no erosions or porosities $(\times 1,500)$

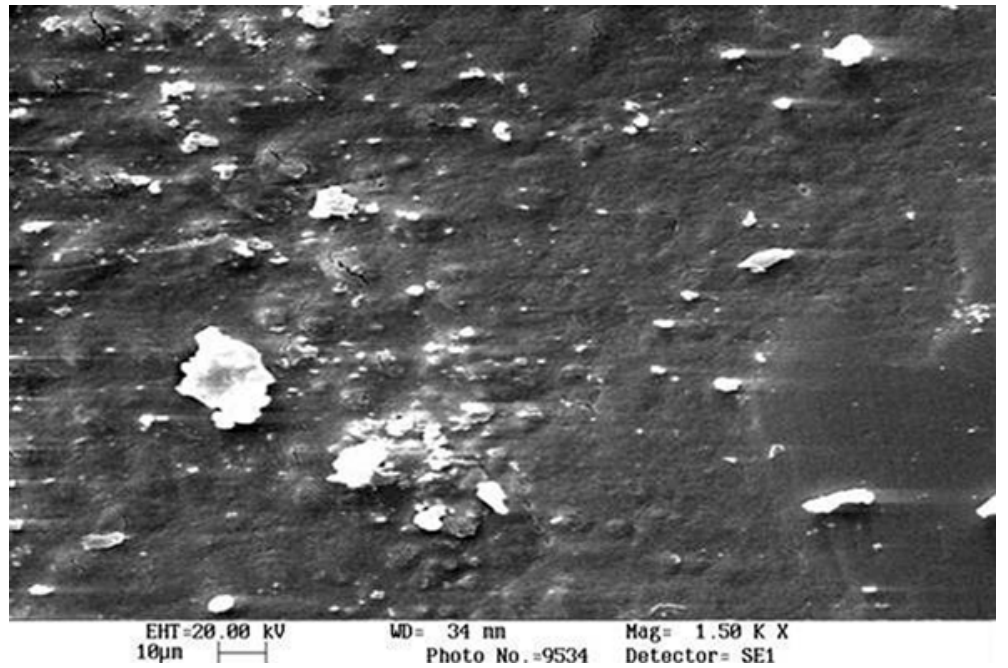

FIGURE 5- SEM micrograph of enamel subjected to bleaching agent containing $10 \%$ carbamide peroxide (Platinum), presenting erosions $(\times 1,500)$

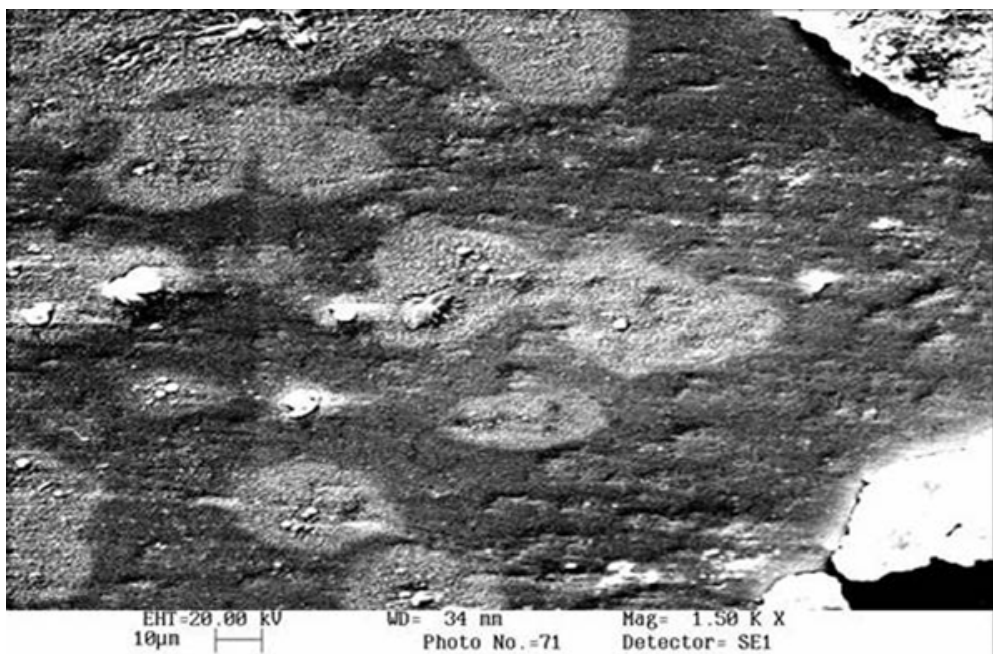

FIGURE 4- SEM micrograph of enamel exposed to a bleaching agent containing $7.5 \%$ hydrogen peroxide (Day White $2 Z$ ), presenting erosions $(\times 1,500)$ 
enamel treated by the different bleaching agents.

\section{DISCUSSION}

Home tooth bleaching has been widely used because it is a simple and effective procedure for removing intrinsic and extrinsic stains. The clinical protocol demands the use of a bleaching product in an individual tray for about 2 to 6 weeks $^{14,16}$. However, modifications of the technique have been introduced, such as different concentrations of carbamide peroxide ( $10 \%$ to $22 \%$ ), as well as $5.5 \%$ to $7.5 \%$ hydrogen peroxide, with the aim of speeding up the dental bleaching time. Thus, the original protocol of vital tooth bleaching, which involves the direct contact of a bleaching agent with the surface of dental structures for an extended period of time (about $8 \mathrm{~h}$ during 6 weeks), has been replaced by faster protocols that demand their use for 1 to $4 \mathrm{~h}$ daily, for 1-12 continuous weeks, depending on the desired level of bleaching ${ }^{23}$. This shorter exposure time is possible due to the increase in the amount of active substance of the bleaching agent in contact with enamel surface in the first hour of application. The degradation of approximately 30 to $40 \%$ carbamide peroxide and hydrogen peroxide ${ }^{21}$ occurred in the first $4 \mathrm{~h}$ of agent application ${ }^{28}$ releases free radicals that break carbon rings of high molecular weight into smaller and clearer molecules ${ }^{14}$. Moreover, no alterations in microhardness and surface micromorphology have been reported in enamel subjected to a shorter period of exposure to home-use bleaching agents. It is suggested that changes might be minimal or inexistent due to a shorter time of contact between agents and dental structures.

Studies evaluated the effects of home-use bleaching agents in the original protocol, on the surface micromorphology of dental structure. SEM analysis showed changes in enamel ${ }^{7,12,19,20,27}$ such as the presence of erosions and porosities that could be justified by an extended time of contact between bleaching agents and the dental structure. Moreover, Gürgan, et al. ${ }^{15}$ (1997) reported changes in surface micromorphology of enamel compared to the control group, which could promote the appearance of erosions and porosities in the dental surface.

The presence of erosions and porosities in enamel has been related to the byproducts, mainly urea and oxygen, from the oxidizing reaction of bleaching agents ${ }^{1,13,17}$. Urea has the property of denaturing proteins present in organic portions of dental structure, with the potential to penetrate through enamel and affect not only the surface, but also interprismatic portion of ename ${ }^{1,13}$. Therefore, the penetration of urea may contribute to the increase of enamel permeability and microstructural alterations.

In addition to urea, Hegedus, et al. ${ }^{17}$ (1999) reported that the oxygen released from carbamide peroxide decomposition is also capable of increasing the porosity of the dental surface, mainly of dentin. The free radicals of oxygen are not specific and may react with organic structures of dental tissues, in which they roam more freely than in mineralized structures. From this aspect, it is important to have in mind that stains on tooth surface are organic composites that degrade by the action of oxygen.

Alterations in the mineral content of enamel and dentin might occur due to the acid properties of these materials and their components $3,5,6,11,22,25,27$. Such alterations may be evaluated by microhardness tests ${ }^{9}$, as performed in the present study. It was observed that the microhardness of human dental enamel subjected to bleaching agents containing $10 \%$ carbamide peroxide or $7.5 \%$ hydrogen peroxide remained constant after 21 days of treatment. This behavior may be attributed to the presence of the artificial saliva as the immersion medium that was capable of maintaining the balance between the demineralization and remineralization processes ${ }^{4,24}$ during the bleaching treatment. Moreover, after $1 \mathrm{~h}$, the bleaching agent was brushed off from dental surface, removing any product residues from contact with enamel after treatment. An increase in the microhardness of enamel subjected to different bleaching agents was also observed, and the same occurred with the control group that remained immersed in artificial saliva during the whole experiment. This was observed in the posttreatment phase due to the remineralizing effect of artificial saliva.

Nevertheless, the surface micromorphology of enamel may be compromised with the use of $10 \%$ carbamide peroxide or $7.5 \%$ hydrogen peroxide bleaching agents. Although such alterations are not clinically noticeable $\mathrm{e}^{12,20}$, it is difficult to determine whether they are microscopically reversible. It is considered that the constant use of fluorides ${ }^{8}$, adoption of adequate measures of oral hygiene, and particularly saliva, may increase microhardness of dental enamel during and after bleaching. These measures also improve surface micromorphological characteristics of dental structures through the deposition of calcium fluoride crystals, in addition to maintaining the balance between the phenomena of demineralization and remineralization. The combination of these factors perpetuates dental rigidity and prevents clinically visible alterations that may change the dental structure subjected to dental bleaching.

\section{CONCLUSIONS}

Bleaching agents containing $10 \%$ carbamide peroxide and $7.5 \%$ hydrogen peroxide may lead to micro-alterations in the surface micromorphology of enamel, but no alterations in microhardness was observed with an application protocol of $1 \mathrm{~h}$ /day during 21 days.

\section{ACKNOWLEDGEMENTS}

This work was supported by The State of São Paulo Research Foundation (FAPESP), grant \# 03/13045-0. 


\section{REFERENCES}

1- Arends J, Jongebloed WL, Goldberg M, Schuthof J. Interaction of urea and human enamel. Caries Res. 1997;26:531-9.

2- Attin T, Kielbassa AM, Schawanenberg M, Helliwig E. The effect of fluoride treatment on remineralization of bleached enamel. J Oral Rehabil. $1997 ; 24(4): 282-6$

3- Attin T, Vollmer D, Wiegand A, Attin R, Betke H. Subsurface microhardness of enamel and dentin after different external bleaching procedures. Am J Dent. 2005;18(1):8-12.

4- Basting RT, Rodrigues AL, Serra MC. Micromorphology and surface roughness of sound and demineralized enamel and dentin bleached with a 10\% carbamide peroxide bleaching agent. Am J Dent. 2007;20(2):97102

5- Basting RT, Rodrigues AL Jr, Serra MC. The effect of $10 \%$ carbamide peroxide bleaching material on microhardness of sound and demineralized enamel and dentin in situ. Oper Dent. 2001;26(6):531-9.

6- Basting RT, Rodrigues AL Jr, Serra MC. The effect of $10 \%$ carbamide peroxide, carbopol and/or glycerin on enamel and dentin microhardness. Oper Dent. 2005;30(5):608-16

7- Bitter NC. A scanning electron microscope study of the long-term effect of bleaching agents on the enamel surface in vivo. Gen Dent. 1998;46(1):84-8

8- Chen HP, Chang CH, Liu JK, Chuang SF, Yang JY. Effect of fluoride containing bleaching agents on enamel surface properties. J Dent. 2008;36(9):718-25

9- Featherstone JD, O’Really MM, Shariati M, Brugler S. Enhancement of remineralization in vitro and in vivo. In: Leach AS, editor. Factors relating to demineralization and remineralization of the teeth. Oxford: IRL; 1986. p. 23-34.

10- Featherstone JD, ten Cate JM, Shariati M, Arends J. Comparison of artificial caries-like lesions by quantitative microradiography and microhardness profiles. Caries Res. 1983;17(5):385-91.

11- Freitas PM, Basting RT, Rodrigues AL Jr, Serra MC. Effects of two $10 \%$ peroxide carbamide bleaching agents on dentin microhardness at different time intervals. Quintessence Int. 2002;33(5):370-5.

12- Fu B, Hoth-Hannig W, Hannig M. Effects of dental bleaching on micro- and nano-morphological alterations of the enamel surface. Am J Dent. 2007;20(1):35-40.

13- Goldberg M, Arends J, Jonegbloed WL, Schuthof J, Septier D. Action of urea solutions on human enamel surfaces. Caries Res. 1983;17(2):10612

14- Goldstein GR, Garber DA. Complete dental bleaching. Chicago: Quintessence Publishing; 1995.

15- Gurgan S, Bolay S, Alacam R. In vitro adherence of bacteria to bleached or unbleached enamel surfaces. J Oral Rehabil. 1997;24(8):6247.

16- Haywood VB, Heymann HO. Nightguard vital bleaching. Quintessence Int. $1989 ; 20(3): 173-6$

17- Hegedüs C, Bistey T, Flora-Nagy E, Keszthelyi G, Jenei A. An atomic force microscopy study on the effect of bleaching agents on enamel surface. J Dent. 1999;27(7):509-15.

18- Landis J, Koch GG. The measurement of observer agreement for categorical data. Biometrics. 1977;33(1):159-74.
19- Lee CQ, Cobb CM, Zargartalebi F, Hu N. Effect of bleaching on microhardness, morphology and color of enamel. Gen Dent. 1995;43(2):158-62.

20- Markovic L, Jordan RA, Lakota N, Gaengler P. Micromorphology of enamel surface after vital tooth bleaching. J Endod. 2007;33(5):607-10.

21- Marshall MV, Gragg PP, Packman EW, Wright PB, Cancro LP. Hydrogen peroxide decomposition in the oral cavity. Am J Dent. $2001 ; 14(1): 39-45$

22- McCracken MS, Haywood VB. Demineralization effects of 10 percent carbamide peroxide. J Dent. 1996;24(6):395-8.

23- Mokllis GR, Matis BA, Cochran MA, Eckert GJ. A clinical evaluation of carbamide peroxide and hydrogen peroxide whitening agents during daytime use. J Am Dent Assoc. 2000;131(9):1269-77.

24- Oliveira R, Basting RT, Rodrigues JA, Rodrigues Jr AL, Serra MC. Effects of a carbamide peroxide agent and desensitizing dentifrices on enamel microhardness. Am J Dent. 2001;16(1):42-6.

25- Rodrigues JA, Basting RT, Serra MC, Rodrigues LA Jr. Effects of $10 \%$ carbamide peroxide bleaching materials on enamel microhardness at different time intervals. Am J Dent. 2001;14(2):67-71.

26- Serra MC, Cury JA. The in vitro effect of glass-ionomer cement restoration on enamel subjected to a demineralization and remineralization model. Quintessence Int. 1992;23(2):143-7.

27- Smidt A, Weller D, Roman I, Gedalia I. Effect of bleaching agents on microhardness and surface morphology of tooth enamel. Am J Dent. 1998;11(2):83-5

28- Wattanapayungkul P, Matis BA, Cochran MA, Moore BK. A clinical study of the effect of pellicle on the degradation of $10 \%$ carbamide peroxide within the first hour. Quintessence Int. 1999;30(11):737-41. 